\title{
MANAGEMENT METHODS AND CONCEPTS FOR BUILDING COMPETITIVE ADVANTAGE IN HOSPITALITY COMPANIES
}

\author{
BEATA GIERCZAK \\ University of Rzeszów, Chair of Tourism Economy, Department of Economics and Management \\ Mailing address: Beata Gierczak, University of Rzeszów, Department of Economics and Management, \\ 3 Towarnickiego Street, 35-959 Rzeszów, tel.: +48 17 8721849, fax: +48 178721265 , \\ e-mail: beatagierczak@ur.edu.pl
}

\begin{abstract}
Introduction. Competitive advantage determines the success of modern enterprises, such as hospitality companies, on the market. In turn, competitive advantage is gained as the result of skillful management, taking into account the factors that characterize the company environment. In the management process, methods and concepts that, when properly applied, facilitate the company's innovative activities play the key role, thus contributing to building competitive advantage. The purpose of this paper is to specify and characterize the methods and management concepts most commonly used by hospitality companies in the process of building competitive advantage. The core benefit of these considerations is that they serve to identify those activities of hospitality companies in which the analyzed methods and concepts found practical application. The final part of the article is devoted to an attempt to identify barriers and problems that significantly limit the use of these methods and concepts. Material and methods. In order to achieve this objective, a survey and interviews were carried out in all three- and four-star hotels in the Rzeszów area in the first quarter of 2012. Results. The results revealed that the concept most commonly used by hoteliers was knowledge-based organization (knowledge management), followed by outsourcing, benchmarking and internal competition, respectively. Conclusions. The study also demonstrated that the managers of these hospitality companies significantly lacked substantive knowledge of emerging "market" management methods and concepts.
\end{abstract}

Key words: management methods and concepts, competitive advantage, hospitality company, hotel services, management, tourism

\section{Introduction}

The presence and, above all, the development of hospitality companies in today's market is dependent on careful observation and fast analysis of both local and global phenomena. The main forces of transformation in the hotel services market include competition, constant change in customer requirements, rapid development of information technology and, in the broad sense, innovation.

A company's ability to adapt to and shape these changing conditions [1] determines its competitiveness. The concept of achieving and maintaining a company's competitiveness is a general way of dealing with competition both in the short and long term. Company competitiveness is also seen as a process in which market participants, while pursuing their interests, try to introduce more competitive prices, better quality or other characteristics affecting decisions to enter into transactions [2].

Methods and management concepts have a special place among the factors determining the competitiveness of hospitality companies. They determine not only the pace and direction of the development of service companies, but also greatly affect their competitive position. They help some companies to achieve market leadership while enabling others to provide improvements and maintain their competitive position [3]. Modern management methods are usually transferred in full from countries with higher levels of economic development where they have been developed and used successfully [4]. Therefore, the ability to rapidly implement an effective method is a test for a well-run company, and proves its ability to develop, while also determining its competitive advantage.

The most widely accepted definition is that competitive ad- vantage is the superior positioning of a company in relation to its competitors. This means that the company is more efficient than its competitors, which allows it to better meet the expectations of investors, managers and employees [4]. As a result, "the essence of competitive advantage is the fact that the company is doing something better and thus achieves better results" [6]. Competitive advantage is also the ability to continually add value that is recognized by company customers. It has a variety of sources and is influenced by various factors. In small companies competitive advantage can be built by drawing attention to four main sources. These are: focusing on the client, paying attention to quality, focusing on innovation and providing reliable service [7].

These advantages are rooted in effective marketing, staff training, the choice of suppliers and the efficiency of distribution channels, changes in management style and the formation of a new organizational culture, as well as research and development processes, innovation growth and modernization of production [7]. Competitive advantage is achieved by developing new resources, changing the quality or configuration of existing resources and establishing new methods of presentation and utilization [1].

Also, the effectiveness of a hospitality company's economic activities depends increasingly on its competitive strategy, which is based on in-depth analysis of factors that are key sources of competitive advantage [1].

The traditional Porter's model developed in the early eighties distinguished two main competitive advantages [8]:

» low-cost advantage, which is the basis of cost leadership strategy,

» differentiation (standing out) advantage, which is the ba- 
sis of differentiation strategy.

However, all companies wishing to stand out in quality must take into account the increase in costs, which means higher prices, which in turn reduces the number of customers. That is why most companies choose to focus on the strategy of limiting their activities to the so-called market niches. It is worth mentioning that, according to Porter, choosing one of the ways to compete in the sector automatically excludes the other, since he considered these advantages mutually exclusive [8]. Subsequent business experience has shown that this assumption was wrong.

Pierścionek presents a slightly wider perception of the problem of competitive advantages [9]. In addition to the already mentioned quality, cost and time advantages, he lists advantages resulting from: a dominant position on the market, a high level of diversification and a high degree of co-operation with selected competitors. The concepts developed by Kay, Hamel and Prahalad deserve special attention among other concepts of the sources of competitive advantage.

According to Kay, a company's distinctive business capabilities are the source of its competitive advantage [10]. A company is successful only when it recognizes its abilities correctly and chooses the most suitable market. For him the main sources of competitive advantage are architecture, reputation, innovation and strategic resources. Innovation can apply to a product or technology or to systems of organization and management. With regard to originality, he distinguished original innovation and imitation. The former is a source of long-term competitive advantage, whereas the latter can produce an unstable advantage.

The second concept of the sources of competitive advantage, developed by Hamel and Prahalad, draws attention to the role of innovation. The authors of the concept argue that the primary source of a company's competitive advantage is its ability to create innovations resulting from its core competencies. Core competences are a set of skills, knowledge and technology that deliver added value to the customer, ensure uniqueness, and make it possible to introduce a range of new products. Core competences can and should be created. This requires a vision of market developments and active participation in both the transformation of the industry and the process of competition for new resources and skills [10].

The stability of the company's competitive position is based on the sustainability of the created or achieved advantage. If this advantage is not permanent and cannot be defended, the company's competitive position will be unstable. The problem of defending the achieved advantage is associated with many factors [11].

Hamel and Prahalad suggest that the sustainability of competitive advantage is largely determined by three factors [12]:

» the extent to which the offered values comply with the structure of buyers' preferences,

» the difficulty with which competitors acquire the resources and skills that enable the company to have competitive advantage,

» the sustainability of resources and skills over time, and their relevance to the development of new product-market configurations.

A similar view is presented by Carr, Hard and Trahant, who admittedly acknowledge that the main factors which determine the competitiveness of a company are the product and its quality, while nevertheless asserting that in developing long-term strategies building professionalism is much more important. They define professionalism as the collective learning of an or- ganization, regardless of whether it applies to a product or service. To ensure professionalism, a company's activities must extend beyond the traditional functioning of the various departments to ensure proper communication of market needs and technological potential [13].

Furthermore, Karlof, who equates competitive advantage with strategic advantage, believes that long-term survival and expansion of activities indeed depend on intensive and continuous learning. The desire to acquire new knowledge is an essential contribution to the permanent renewal of competitive advantage [14]. However, in the literature the view is becoming increasingly common that a systematic combination of many competitive advantages (so-called superiority complex or combined) determines the success of the company, and that partial competitive advantage is only an extreme case of the general model [15]. Success in the market and thus the competitive position is contingent upon a number of factors. The ability to continually learn, acquire new knowledge and respond quickly to change play a particularly prominent role. For, what was recognized as a key factor for the success of a company in a particular area yesterday is out-of-date today, and the winner is the one who can adjust to these changes the fastest.

The purpose of this article is to show how different management methods and concepts contribute to the process of building competitive advantage in hospitality companies. The scope is limited to those methods that are the most widely accepted, taking into account in which areas of hotel activities they are used.

\section{Material and methods}

The study was conducted from January 2011 to January 2012 and included all three- and four-star hotels in the Rzeszów area - a total of 13 hotels (tab. 1). Several factors influenced the choice of the abovementioned hotel types. First of all, they were the only hotels with a high standard of services in Rzeszów ${ }^{1}$. In addition, their organizational structure and the variety of services they provide suggested that their management practices would feature management concepts and methods aimed at improving their functioning. The basic tool used in the study was a questionnaire containing 24 questions. It was divided into two main sections:

1. Section one - with questions on how the hotel is organized and what services it provides,

2. Section two - mainly concerned with the hotel's management methods and concepts and all related aspects.

One important aspect of the second part of the questionnaire was a question concerning the sources of information used by respondents, in order to improve knowledge of management methods and concepts. The options included: training outside the company, internal training, conferences, contacts with experts and specialists, knowledge from specialist articles, books and publications, and the media. The choice of scale in the assessment of the effectiveness of the sources of knowledge was the following: 0 - not used, 1 - ineffective, 2 - slightly effective, 3 - effective, 4 - very effective, 5 - ideally effective. Simple, standardized interviews with selected hotel directors or general managers also helped to complete and refine the questionnaire. 
Table 1. List of all hotels in Rzeszów, which were subjected to the study

\begin{tabular}{|l|c|c|c|c|}
\hline Hotel name & Type & Type of organizational structure & Presence in the market & Size of the company - number of employees \\
\hline Ambasadorski & ${ }^{* * * *}$ & flat & 7 years & medium (51-250 employees) \\
\hline Classic & ${ }^{* * *}$ & flat & 9 years & small (up to 50 employees) \\
\hline Ferdynand & ${ }^{* * *}$ & flat & 6 months & small (up to 50 employees) \\
\hline Forum & ${ }^{* * *}$ & flat & 4 years & small (up to 50 employees) \\
\hline Grand & ${ }^{* * *}$ & flat & 6 years & large (over 250 employees) \\
\hline Hetman & ${ }^{* * *}$ & hierarchical & 4 years & small (up to 50 employees) \\
\hline Horyzont & ${ }^{* * *}$ & flat & 7 years & medium (51-250 employees) \\
\hline Hubertus & ${ }^{* * *}$ & flat & medium (51-250 employees) \\
\hline Icam House & ${ }^{* * *}$ & flat & headquarters 15 years, hotel 2 years & small (up to 50 employees) \\
\hline Park Hotel & ${ }^{* * *}$ & flat & 11 years & medium (51-250 employees) \\
\hline Prezydencki & ${ }^{* * *}$ & hierarchical & 8 months & small (up to 50 employees) \\
\hline Twierdza & ${ }^{* * *}$ & flat & 5 years & small (up to 50 employees) \\
\hline Villa Riviera & ${ }^{* * *}$ & flat & &
\end{tabular}

Source: own study based on questionnaire.

\section{The methods and concepts used in modern management - characteristics}

The functioning of an organization that provides hotel services in a competitive environment depends on its continuous development and the improvement of its market position by making changes.

The dynamics of the change in factors in the development of the modern hospitality market result in a constant search for new methods and management concepts that serve to distinguish the organization and its services on the market, thereby leading to competitive advantage [16]. New concepts and methods in company management emerge constantly which provide market participants with a range of solutions and ideas to effectively improve their functioning by increasing the competitiveness and profitability of the organization and by improving employee and customer satisfaction.

Opportunities to improve the management result from the availability of a large number of concepts and methods to assist in this process. The applicability of these concepts to increasingly complex problems, and above all positive experiences with their implementation ${ }^{2}$ show that the use of modern, innovative methods has become a necessity. While these methods are continually being enriched, there are also new ones which include different areas of company activities or which have a cross-cutting nature.

The choice of a variety of methods and knowledge of the company and its weaknesses enable improvements to be rapidly introduced in the required area. Competitive advantages are sought in many different company areas, such as [21]:

» in marketing - the most modern and appropriate methods are selected here to allow commercialization of new products (services), shaping distribution channels and customer relationships,

» in production - the use of methods supporting work related to the startup of new production, production control and the production process,

» in logistics - shaping the supply chain, creating systems for customer service logistics by implementing modern information systems to facilitate cooperation and communication with both customers and suppliers,

» in research and development - methods and concepts supporting preparatory work and development,

» in human resource management - the use of methods which ensure proper selection of employees, their development, the development of career paths, motivation, evaluation, etc. The activities are focused primarily on the mobilization of workers, because they are one of the most important strategic resources of service companies.

Therefore, it is important to select methods and management concepts appropriate to the needs of a company and then to properly carry out the process of their implementation. Skillfully developed and consistently implemented methods, contribute to competitive advantage and ultimately sustain, in the long term, a competitive position which is difficult to imitate. The most frequently mentioned management methods and concepts include reengineering, internal competition and the development of quality, outsourcing, benchmarking, knowledgebased organization (knowledge management), lean management, kaizen, time and hoshin based management and Six Sigma. The scope of this article is limited to those which have been used by the surveyed hotel managers.

1. Outsourcing - (outside- resource- using) is defined as "a project involving the contracting out of an organizational company's functions to a third-party" [22]. The concept of outsourcing also involves the creation of a new model for services. It is believed that a company can dispense with services that are not critical and may be provided by other specialist companies [17]. In the concept of outsourcing, costs play a key role, especially with regard to their reduction. Hence, it is suggested that outsourcing be used with caution in relation to primarily simple services and be integrated only slightly into the core activity of the company.

2. Knowledge-based organization (knowledge management) - knowledge and information is and will be important factors for company competitiveness, and skillful management of knowledge is a tool for opening up new horizons for companies. Guldenberg and Eschenbach distinguish two aspects of an organization that are based on knowledge: institutional and functional. In the institutional sense, such an organization is a social system with a structure of communication and information that allows interaction between its participants. Functional 
organization, based on knowledge, is treated as a concept that is the basis for all management concepts aimed at making decisions, solving problems, and initiating change [17]. However, knowledge-based organization, understood as a management concept, is based on a totality of expertise which is shared by its individual contributors - knowledge that is constantly enriched and developed, then "shared" with the company [17].

3. Benchmarking - Spendolini, one of the leading inventors of benchmarking, defines it as a continuous, systematic process for testing products, services and processes occurring within a company which are recognized as representing best practices, in order to promote the company's achievements [23, 24]. Among those who define benchmarking slightly different are Sherman and Zhu, who believe that it is a method for improving the functioning of the company by increasing its income, improving quality and reducing operating costs [25]. The essence of benchmarking is captured by the Japanese word dantotsu. It means an earnest desire to be the best of the best, an active process designed to achieve the best performance by changing individual operations [26].

4. Internal competition and the development of quality the definition and the aim of this concept is to increase employee productivity. The employee who is the most productive wins the competition and is awarded a pay raise and promotion. Employee performance is evaluated on the basis of established criteria [17].

5. Reengineering is a fundamental rethinking and radical redesign of business processes, leading to groundbreaking improvements in performance in such areas as cost, quality, service and speed [24]. At the heart of reengineering is the assumption that we should break up the functioning of the modern enterprise system, currently based on task orientation, in favor of an organizational approach that views an organization as a multitude of business processes which create value [27]. It is quite often identified with the word "downsizing" (reduction), as it is mainly associated with a reduction in employment and the desire to reduce costs. This method is difficult to accept mainly because the whole company has to change at the same time. It destroys the existing organizational order, position system and roles. As the experience of companies which have benefited from reengineering shows, the main problem is not to develop innovative processes, but to change the mentality of workers [22].

\section{Management methods and concepts in hospitality companies - results and conclusions of the study}

The research conducted among the directors or managers of the aforementioned hotels in Rzeszów showed that for the majority - 9 - the management methods and concepts contributed to achieving competitive advantage. This result was not confirmed by 4 managers.

The results, however, did not confirm that these hospitality companies used management methods and concepts to the ex- tent and within the scope ${ }^{3}$ shown by studies on the use of various management methods carried out systematically by Bain \& Company in various companies throughout the world [28]. Above all, there is a noticeable lack of technical knowledge among managers, coupled with a tendency to misinterpret the management methods and concepts ${ }^{4}$ they use, which might seem to be among those most commonly reported in the literature. Figure 1 below shows the methods and concepts which were and are used and tested most often by hospitality companies in the process of building competitive advantage.

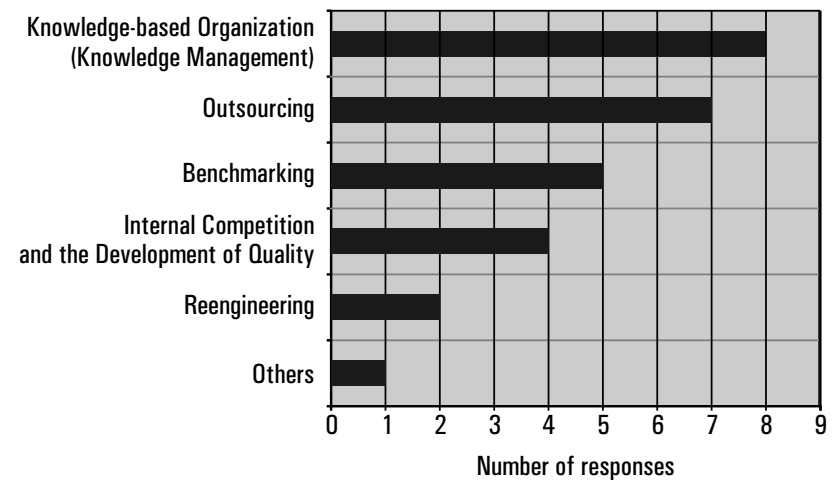

* It was possible to select multiple methods.

Source: authorial study based on research.

Figure 1. Management methods and concepts used by hospitality companies

An organizational approach based on knowledge (knowledge management) is the most popular approach among hoteliers, being used by eight of the surveyed hotels. Their managers and directors often stress the fact that workers who are always willing to learn and are open to change are a major source of potential for their companies. Therefore, management gives employees the opportunity to improve and update their knowledge using different sources. According to the survey, training outside the company is seen as a very effective means of gaining and expanding knowledge on modern methods and concepts of management -24 points. The following also appear effective: inhouse training - 17 points, scientific knowledge (books and publications) -13 points, and the media -10 points.

Another feature of knowledge-based organization is its ability to capitalize on experience resulting from numerous contacts with customers, suppliers and the local community to create new knowledge. Contacts with competitors also lead to valuable knowledge, and this advantage was appreciated by three of the eight managers who use this concept. They emphasize almost unanimously that the concept applies to all activities of a hospitality company, and is equally implemented in all of the hotels, but mainly in those areas or departments whose employees are responsible for direct contact with customers. The difference is more frequent employee "refresher training" in customer service and the ability to speak foreign languages.

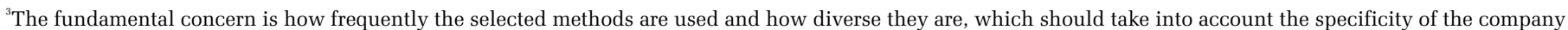

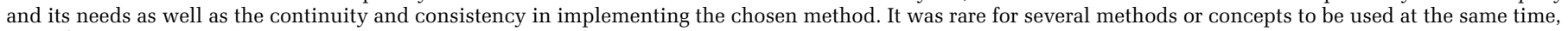
even if such an approach had merits and organizational justifications.
} 
An important feature of knowledge-based organization which draws the attention of the managers in the surveyed hotels is broad-based collaboration with the client, which provides knowledge of them and their needs, while also fostering faster and more efficient work.

Outsourcing, chosen by 7 hoteliers, came in second among the management methods and concepts most widely used in the process of building competitive advantage. It is the management method that has probably been the most popular in Poland in recent years, and its use in the surveyed hotels was, for many reasons, unjustified and puzzling ${ }^{5}$.

Studies have shown that in three- and four-star hotels in Rzeszów outsourcing is most often used in relation to laundry services, cleaning services, maintenance services, cultural-entertainment services and transport. Occasionally, however, outsourcing is used for marketing (advertising) and services related to translation and simultaneous interpretation equipment (only in 2 hotels). It is also worth mentioning that outsourcing is used for food service, including confectionery (one hotel).

Benchmarking was ranked third. The results of the study show that it was or is used by 5 three- and four-star hotels in Rzeszów. This method was introduced in order to improve quality, reduce costs and increase customer satisfaction. Improved financial performance and increased competitive advantage were equally important arguments for implementing this creative innovation.

When choosing who to task with introducing and implementing this method, the employee's experience and knowledge mattered, as did their position in the company. The study also confirms existing practices relating to the selection of a partner in the process of benchmarking. External, or "competitive", benchmarking is especially popular among "the hoteliers". The comparison focuses on hotels of the same or higher category located in the region. However, the subject criterion concerning the hotel being compared indicates the use of benchmarking processes (planning, complaints, management and organization) and results (quality of consumer service, the rate of flow of documents).

Despite the surprising focus on adapting innovations only in the hospitality industry, the surveyed hoteliers said they use benchmarking only occasionally or when necessary. Benchmarking is used regularly and is part of the management process in only one of the five hotels surveyed. Three hotel managers do not inform employees about planned activities relating to the introduction of benchmarking, nor do they acquaint them with the method or involve them in its implementation.

Internal competition and the development of quality is another concept used by hotel managers in Rzeszów. Fixed requirements and transparent promotion rules are some of the features specified by the managers and directors. Several emphasize that they consistently adhere to them, which motivates their employees to be more productive and thus enhances competition, which in turn increases the quality of employees' work. Staff assessment "takes place on a regular basis" but, as the managers note, this approach has a drawback due to the number of managerial positions, which depends on the organizational structure of the hotel and the type and quantity of services the hotel provides.

Reengineering is a concept rarely used by hoteliers in the process of building competitive advantage. The analysis of the survey reveals that this concept is used in practice only when the entire company is transformed as a result of changes in management, organizational restructuring and expansion of the hotel as well as diversification of its services.
Most decisions on the selection of the above management methods or concepts result from a desire to improve the current level of quality of hotel services and to increase revenue. Nevertheless, many directors stress that the use of modern management methods and concepts by hospitality companies is quite justified and understandable and also largely results from changes in international competition. Unfortunately, the regularity and effectiveness of the methods and concepts are limited to a large extent by lack of knowledge, and as a result, lack of experience in their implementation. The fear of high costs and skepticism towards what is new and innovative are further arguments mentioned by the management staff.

\section{Conclusions}

Increased competition is a direct result of participation in the common market and requires hospitality companies to take action and implement strategies to improve and sustain competitive advantage [29].

There are many factors that determine a company's ability to build its competitive advantage and thus implement an effective strategy. One of them is certainly the choice of appropriate management methods or concepts, preceded by an in-depth analysis of company and market trends. It is a difficult decision because modern concepts and methods have a wide, multi-sectional nature and require management to possess interdisciplinary knowledge.

However, the mere decision to introduce a method or concept does not guarantee a hospitality company success and a stable market position. The expected changes and improvements are possible only if the selected method is properly and consistently applied in the required areas or processes.

The research presented in this paper shows that managers of hospitality companies significantly lack technical knowledge of emerging "market" management methods and concepts. This in turn results in their being misinterpreted, and thus applied incorrectly or cancelled completely. In the longer term, this results in a lack of expected results, which ultimately discourages managers from applying the management methods or concepts.

Therefore, special attention should be given to actively involving all employees in the process of improvement and development. More emphasis should be placed on training concerning management methods and concepts and on the importance of internal communication. Systematic employee involvement should convince all employees of the need to constantly monitor the processes and to improve them. This, in turn, should enable all employees to instill a philosophy of constant change.

It should also be noted that new management methods and concepts should not be implemented occasionally. A chain of concrete activities should be implemented by any hospitality company that wants to stay in the market. No hotel will be able to secure a stable competitive position if its advantage, with management methods and concepts as its basis, is not based on a permanent factor or influenced by the changing environment.

\section{Literature}

1. Bielski I. (2001). A method of forming competitive advantages. In J. Kotwicz-Jawor (Ed.), Entrepreneurship and competitiveness (pp. 199-203), vol. IV. Warsaw: Bellona. [in Polish] 
2. Cyrkon E. (2000). Compendium of knowledge about the economy. Warsaw - Poznań: PWN. [in Polish]

3. Haffer M. (1997). The benchmarking process as a method of improving enterprise management. Katowice: Wydawnictwo AE Katowice. [in Polish]

4. Ziębicki B. (1998). The methodology of benchmarking in large and small enterprises (in selected U.S. companies). Zeszyty Naukowe AE w Krakowie 506, 117-130. [in Polish]

5. Zimniewicz K. (2009). Modern management concepts and methods. Warsaw: PWE. [in Polish]

6. Bogan Ch.E., English M.J. (2006). Benchmarking as a key to best practices. Gliwice: Wyd. Helion. [in Polish]

7. Fisher R.S., White M.A. (2000). Downsizing in a learning organization: are there hidden costs? Academy of Management Review 25(1), 244-251.

8. Gierczak B. (2013). The influence of strategic alliances on conducting benchmarking in air transport tourism. In R. Pawlusiński (Ed.), Contemporary conditions and problems of tourism development (pp. 215-223). Kraków: Wyd. Instytut Geografii i Gospodarki Przestrzennej UJ. [in Polish]

9. Brodowska-Szewczuk J. (2009). Competitiveness of enterprises and the source of competitive advantage. Zeszyty Naukowe, Seria:Administracja i Zarzqdzanie 80, 92-93. [in Polish]

10. Godziszewski B. (2001). Resource considerations of corporate strategy. Toruń: UMK. [in Polish]

11. Targalski J. (2003). Entrepreneurship and management. Warsaw: Wyd. C.H. Beck. [in Polish]

12. Sopińska A. (1998). The problem of competitive advantages in contemporary economy. Przegląd Organizacji 6, 7-8. [in Polish]

13. Pierścionek Z. (1996). Strategies for company development. Warsaw: PWE. [in Polish]

14. Pierścionek Z. (2003). Competitive and development strategies of companies. Warsaw: PWN. [in Polish]

15. Strategor. (1997). Company management. Warsaw: PWE. [in Polish]

16. Hamel G., Prahalad C.K. (1999). Competing for the future. Warsaw: Business Press. [in Polish]

17. Carr D.K., Hard K.J., Trahant W.J. (1998). Managing the change process. Warsaw: PWN. [in Polish]
18. Karlof B. (1992). Business strategy. Concepts and models a guide. Warsaw: Biblioteka menedżera i bankowca. [in Polish]

19. Ma H. (1999). Constellation of competitive advantage: components and dynamics. Management Decision 37(4), 348355.

20. Maciag J. (2010). The system of service quality management: principles and methods (as demonstrated by tourist and recreational services). Katowice: AWF Katowice. [in Polish]

21. Pałucha K. (2008). Modern methods of production management support. Organizacja i Zarządzanie 2, 69-82. [in Polish]

22. Lendzion J.P., Stankiewicz-Mróz A. (2005). Introduction to organization and management. Kraków: Oficyna Ekonomiczna. [in Polish]

23. Warren C.M. (2002). Benchmarking corporate real estate; fundamentals of measurement. Pacific Rim Property Research Journal 8(4), 277-285.

24. Hammer M., Champy J. (1996). Reengineering the enterprise. Warsaw: Neumann Management Institute. [in Polish]

25. Sherman D.H., Zhu J. (2006). Benchmarking with qualityadjusted DEA (Q-DEA) to seek lower-cost high-quality service with data envelopment analysis: Evidence from a U.S. bank application. Annals of Operations Research 145(1), 301-319.

26. Dahlgaard J.J. et al. (2000). Fundamentals of quality management. Warsaw: PWN. [in Polish]

27. Bendkowski J., Bendkowski J. (2008). Practical management of organizations. managerial competence. Gliwice: Wyd. Politechniki Śląskiej. [in Polish]

28. Kuczewska J. (2007). European benchmarking procedure. Programs and activities. Warsaw: PARP. [in Polish]

29. The usefulness of a variety of management tools for the assessment of managers. (2001). Zarzqdzanie na Świecie 10, 22-28. [in Polish]

Submitted: April 20, 2014

Accepted: July 7, 2014 